\title{
A Case of a Primary Radiation-Induced Malignant Peripheral Nerve Sheath Tumor in the Cauda Equina in a Patient with Neurofibromatosis Type 2
}

\author{
Takafumi Mitsuhara $^{1 *}$, Satoshi Yamaguchi ${ }^{1}$, Masaaki Takeda $^{1}$, Kuniki Eguchi ${ }^{1}$, Mizuki Morishige ${ }^{2}$, Kazuhiko Sugiyama ${ }^{3}$ and Kaoru Kurisu ${ }^{1}$
}

${ }^{1}$ Department of Neurosurgery, Graduate School of Biomedical and Health Sciences, Hiroshima University, 1-2-3 Kasumi, Minami-ku, Hiroshima 734-8551, Japan

${ }^{2}$ Department of Clinical Engineering, Hiroshima University Hospital, Hiroshima, Japan

${ }^{3}$ Department of Clinical Oncology and Neuro-oncology Program, Hiroshima University Hospital, Hiroshima, Japan

\section{Abstract}

Background: Radiation-induced malignant peripheral nerve sheath tumors (MPNSTs) may occur in any irradiated area of the body where primary malignant lesions existed. However, there have been isolated reports regarding the radiation-induced transformation of spinal schwannomas into MPNSTs in patients with neurofibromatosis type 2 (NF2)

Case material: A 47-year-old woman presented with gradually progressive paraparesis, bowel-bladder dysfunction, and acute consciousness disturbance. Fifteen years previously, she had undergone radical hysterectomy with adjuvant intraoperative para-aortic radiotherapy for the treatment of uterine cervical cancer. Magnetic resonance (MR) images of the brain revealed hydrocephalus and multiple intracranial tumors in bilateral oculomotor and vestibular nerves. Spinal MR images revealed numerous tumors in the cervical cord and cauda equina. Signal alteration in the lumbosacral vertebral bodies on MR images, which implies fatty degeneration, suggested that the cauda equina was included in the previous radiation field. Because the patient complained of severe pain in the lower back region and lower extremities, we partially resected the lumbosacral tumors to achieve pain control. Histological examination of the resected tumors revealed the lesions to be MPNSTs. Despite postoperative radiation therapy, the residual tumor regrew. The patient is now under palliative care.

Conclusion: We report a rare case of a primary MPNST in the cauda equina occurring 15 years after the administration of intraoperative irradiation for uterine cancer. In patients with NF2 who undergo irradiation for malignancies, long-term observation is mandatory because tardive malignant transformation may occur in pre-existing schwannomas in the irradiated field.

Keywords: Cauda equina; Intradural; Irradiation; Malignant peripheral nerve sheath tumor; Neurofibromatosis

\section{Introduction}

Malignant peripheral nerve sheath tumors (MPNSTs) are malignant tumors arising from a peripheral nerve or extraneural soft tissue that exhibits nerve sheath differentiation [1]. Although the incidence of MPNSTs in the general population is $0.001 \%[2,3]$, the incidence is $5 \%$ in patients with neurofibromatosis type 1 (NF1) $[2,4,5]$. Conversely, MPNST is rarely associated with neurofibromatosis type 2 (NF2). Another predisposing factor for MPNSTs is a history of radiation therapy [6]. MPNSTs can occur in any area of the body that was exposed to irradiation to treat a primary malignancy. However, primary radiotherapy-induced MPNSTs in spinal intradural structures are very rare, with only 4 cases reported so far [6-8]. In this study, we discuss a new case of a primary radiotherapy-induced MPNST of the cauda equina in a patient with NF2.

\section{Case Material}

A 47-year-old woman presented with gradually progressive paraperesis, bowel-bladder dysfunction, and acute consciousness disturbance. Physical examination revealed slight bilateral facial nerve palsy, hearing disturbance in the right ear, and paraperesis with muscle atrophy in her right leg. Her skin exhibited no café au lait spots or terminal nerve twigs. Fifteen years previously, she had undergone radical hysterectomy with adjuvant intraoperative paraaortic radiotherapy $(22 \mathrm{~Gy})$ for the treatment of stage Ib uterine cervical cancer at another hospital. She had remained in good health without metastasis after postoperative chemotherapy until the current presentation. Magnetic resonance (MR) images of the brain revealed hydrocephalus and multiple intracranial tumors in bilateral oculomotor and vestibular nerves (Figure 1). Spinal MR images revealed small tumors in the cervical cord and massive tumors in the cauda equina (Figure 2). Signal alteration in the lumbosacral vertebral bodies, which implies fatty degeneration, on MR images suggested that the cauda equina was included in the previous radiation field.

Although a ventriculoperitoneal shunt eliminated her headache and restored her consciousness, the patient complained of severe pain in her lower back region and lower extremities. Because her the pain in her right leg and bladder and bowel dysfunction were so severe that nerve function below the L5 level was considered unserviceable, we decided to remove the tumor in the cauda equina to achieve pain control. Partial removal of the tumor was performed via L3-5 lumbar laminectomy. Multiple reddish gray-colored tumors showed firm attachment to and strongly compressed the intact nerve roots. After internal decompression of the tumor, dural plasty with fascia was performed to achieve external decompression.

*Corresponding author: Takafumi Mitsuhara, Department of Neurosurgery, Graduate School of Biomedical and Health Sciences, Hiroshima University, 1-2-3 Kasumi, Minami-ku, Hiroshima 734-8551, Japan, Tel: +81 82254 5227; Fax: +81 82 254 5229; E-mail: mitsuhar@hiroshima-u.ac.jp

Received December 10, 2012; Accepted December 26, 2012; Published December 28, 2012

Citation: Mitsuhara T, Yamaguchi S, Takeda M, Eguchi K, Morishige M, et al (2013) A Case of a Primary Radiation-Induced Malignant Peripheral Nerve Sheath Tumor in the Cauda Equina in a Patient with Neurofibromatosis Type 2. J Spine 2:129. doi:10.4172/2165-7939.1000129

Copyright: (c) 2013 Mitsuhara T, et al. This is an open-access article distributed under the terms of the Creative Commons Attribution License, which permits unrestricted use, distribution, and reproduction in any medium, provided the original author and source are credited. 
Citation: Mitsuhara T, Yamaguchi S, Takeda M, Eguchi K, Morishige M, et al. (2013) A Case of a Primary Radiation-Induced Malignant Peripheral Nerve Sheath Tumor in the Cauda Equina in a Patient with Neurofibromatosis Type 2. J Spine 2:129. doi:10.4172/2165-7939.1000129

Histological examination of the specimen revealed infiltrating tumors composed of spindle cells arranged in a herringbone pattern with irregular nuclei and nuclear hyperchromasia (Figure 3). Immunohistological examination revealed focal positivity for S-100P in the tumor cells. The Ki-67 index of $47 \%$ confirmed the highly proliferative nature of the tumor. These histopathological findings were consistent with a diagnosis of MPNST.

The patient was relieved of the persistent lumbar pain after surgery by decompressing the spinal canal. She received adjuvant radiotherapy at a total dose of 50.4 Gy fractioned over 28 sessions: 36 Gy for the entire spine and brain and a booster dose of $14.4 \mathrm{~Gy}$ for the lumbosacral lesion. Despite these treatments, subsequent MR images revealed a residual tumor refilling the resected tumor cavity. The patient has been transferred to another hospital for palliative care.

\section{Discussion}

\section{MPNST: Location and Association with NF1 and NF2}

MPNSTs usually affect adults ranging in age from 20 to 50 years without a distinct gender preponderance, and it is rare in children younger than 6 years $[9,10]$. The most common locations are the trunk, limbs, and head and neck [5], and MPNSTs rarely affect the intradural components of the cerebrospinal axis.

The incidence of MPNSTs in the general population is $0.001 \%[2,3]$ but, the incidence is $5 \%$ among patients with NF1 $[2,4,5]$. During their lifetimes, $8-13 \%$ of patients with NF1 develop MPNSTs arising from the malignant transformation of pre-existing plexiform neurofibroma. MPNST remains the single biggest contributing factor to reduced life expectancy in NF1 [11-13]. Such malignant transformation of schwannomas in patients with NF2 is extremely rare.
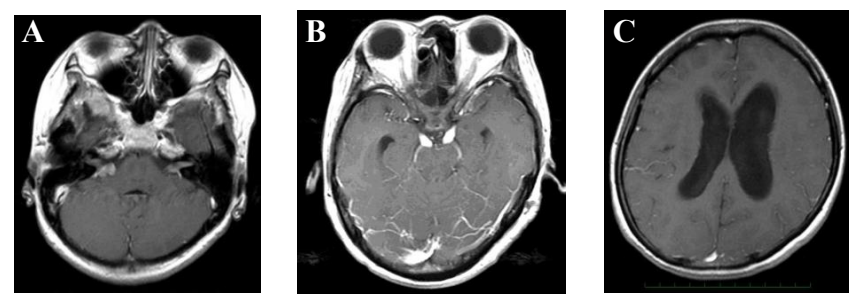

Figure 1: Initial cranial magnetic resonance images with gadolinium revealing bilateral vestibular tumors invading the internal auditory canals $(\mathbf{A})$, bilateral oculomotor tumors (B), and ventricular dilatation (C).
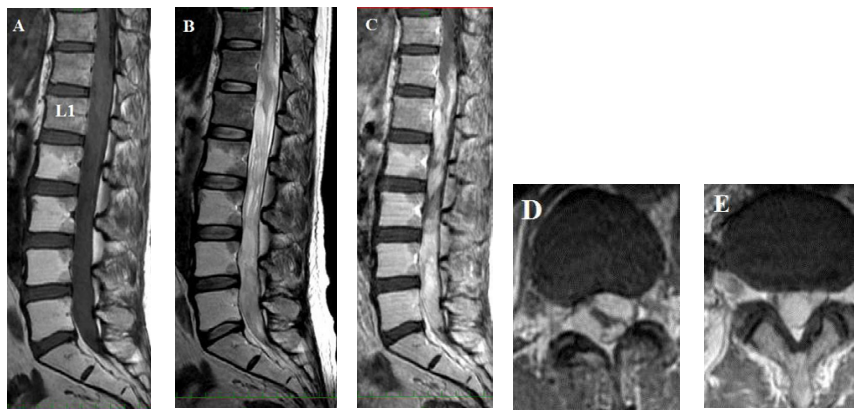

Figure 2: Initial magnetic resonance images of a lumbosacral lesion revealing a massive tumor completely infiltrating the spinal canal from the T11 leve to the sacral level (A: T1-weighted sagittal image, B: T2-weighted sagittal image, C: T1-weighted sagittal image with gadolinium, D: T1-weighted axial image with gadolinium at the T12/L1 level, E: T1-weighted axial image with gadolinium in at the $L 4 / 5$ level)
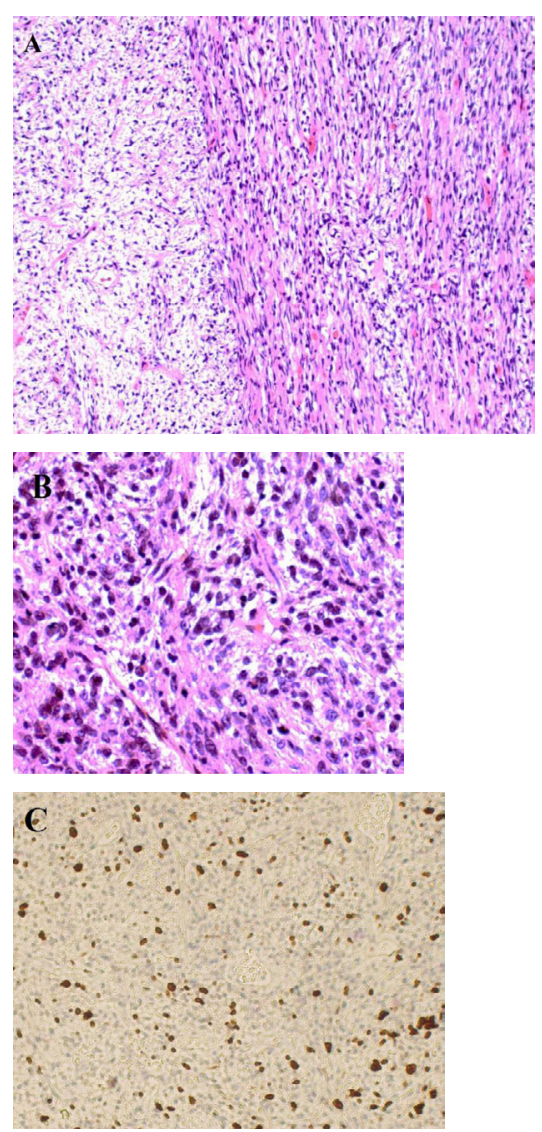

Figure 3: Representative hematoxylin and eosin-stained lumbosacral surgical specimen (A: magnification $\times 200$, B: magnification $\times 400$ ) and $\mathrm{Ki}-67$ index elevated up to approximately $40 \%$ (C: magnification $\times 200$ ).

When MPNSTs affect intracranial structures, they arise de novo in $50 \%$ of cases, and MPNSTs associated with NF1 and NF2 account for $13 \%$ and $6 \%$ of all of these tumors, respectively [14]. Because spinal MPNSTs usually affect nerve roots, primary spinal intradural MPNSTs are rare. $\mathrm{Xu}$ et al. reviewed 24 cases of primary spinal intradural MPNSTs [15]. The median patient age was 35 years (range: $4-70$ years), and $20 \%$ of the patients were children less than 14 years old. With regard to tumor site, $33.3 \%$ of the tumors were cervical, $25 \%$ were in thoracic, and $41.6 \%$ were located in the lumbar and sacral spine. In total, 4 of 24 tumors (16.7\%) occurred in patients with NF1, whereas none of these tumors developed in patients with NF2.

In the present case, the patient had bilateral vestibular tumors, and she was diagnosed with NF2. As mentioned previously, there is no other reported case of primary spinal intradural MPNSTs associated with NF2.

\section{Radiation-induced MPNSTs}

Radiation increases the risk of malignant transformation of a tumor or the risk of inducing additional tumor formation within the radiation field $[6,13,14]$. The deleterious effect of radiation on peripheral nerves was described initially in early animal experimental work $[16,17]$ and supported by reports of nerve sheath tumors occurring in previously irradiated fields [18]. The incidence of radiation-induced MPNSTs reported in large series ranged from $5.5 \%$ to $11 \%[5,6]$.

Although details of the radiation protocol that the patient 
Citation: Mitsuhara T, Yamaguchi S, Takeda M, Eguchi K, Morishige M, et al. (2013) A Case of a Primary Radiation-Induced Malignant Peripheral Nerve Sheath Tumor in the Cauda Equina in a Patient with Neurofibromatosis Type 2. J Spine 2:129. doi:10.4172/2165-7939.1000129

Page 3 of 3

\begin{tabular}{|c|c|c|c|c|c|c|c|c|c|c|}
\hline No & Author & $\begin{array}{l}\text { Age / } \\
\text { sex }\end{array}$ & NF & $\begin{array}{l}\text { Previous } \\
\text { disease }\end{array}$ & $\begin{array}{l}\text { Years after } \\
\text { irradiation }\end{array}$ & Level & Removal & Adjuvant therapy & Metastasis & Outcome \\
\hline 1 & $\begin{array}{l}\text { Seppaala and } \\
\text { Haltia [8] }\end{array}$ & $13 / M$ & NF1 & Wilms' tumor & 12 years & Lumbosacral & Incomplete & Nul & Brain, Systemic & Dead at $2 \mathrm{mo}$. \\
\hline 2 & Amin et al. [6] & $38 / \mathrm{M}$ & No & $\begin{array}{l}\text { Testicular } \\
\text { seminoma }\end{array}$ & 10 years & Lumbosacral & Biopsy & Chemotherapy & Null & Null \\
\hline 3 & $\begin{array}{l}\text { Adamson et } \\
\text { al. [7] }\end{array}$ & $37 / M$ & No & $\begin{array}{l}\text { Hodgkin's } \\
\text { lymphoma }\end{array}$ & 6 years & Cervical & Incomplete & Radiotherapy & No & $\begin{array}{l}\text { Dead after } 1 y \text { and a } \\
\text { few months }\end{array}$ \\
\hline 4 & $\begin{array}{l}\text { Adamson et } \\
\text { al. [7] }\end{array}$ & $30 / F$ & No & $\begin{array}{l}\text { Hodgkin's } \\
\text { lymphoma }\end{array}$ & 16 years & Cervical & Incomplete & No & No & Dead after 1y \\
\hline 5 & Present case & $47 / F$ & NF2 & $\begin{array}{l}\text { Cervical } \\
\text { cancer }\end{array}$ & 15 years & Lumbosacral & Incomplete & Radiotherapy & No & Alive at $6 \mathrm{mo}$ \\
\hline
\end{tabular}

Table 1: Summary of this case and previously reported cases of radiation-induced primary intradural malignant peripheral nerve sheath tumors.

underwent 15 years ago were not available, fatty degeneration of the marrow of the lumbosacral vertebral bodies strongly suggested that the cauda equina was included in the radiation field. Thus, we believed that the MPNST in the present case was caused by radiation-induced malignant transformation of a pre-existing schwannoma in the cauda equina. We reviewed 5 cases of intradural MPNSTs associated with previous radiotherapy, including our case (Table 1) [6-8]. All patients were less than 50 years old and had a prior history of radiotherapy for malignancies. One tumor developed in a patient with NF1, and the present case was of a patient with NF2. All patients underwent surgery, 2 patients received postoperative radiotherapy, and 1 patient received chemotherapy. Although a negative surgical margin is the most significant factor for survival and local control for MPNSTs, complete removal without morbidity is impossible in cases of spinal intradural MPNSTs [3,15]. Among the cases of MPNSTs associated with previous radiotherapy, 3 cases had a fatal outcome within a year. Four of the 5 cases showed a latent period of more than 10 years after radiotherapy, and therefore, long-term observation is mandatory for patients who undergo radiotherapy along the spinal column.

\section{Conclusion}

We report a rare case of a primary spinal intradural MPNST in a patient with NF2 occurring 15 years after intraoperative irradiation for uterine cancer. If radiation is administered to patients with NF2, the patients should be carefully followed-up, and the possibility of malignant transformation of pre-existing schwannomas induced by initial irradiation should be kept in mind if the radiation field includes the spinal cord.

\section{References}

1. Louis DN, Ohgaki H, Wiestler OD, Cavenee WK, Burger PC, et al. (2007) The 2007 WHO classification of tumours of the central nervous system. Acta Neuropathol 114: 97-109.

2. Gupta G, Maniker A (2007) Malignant peripheral nerve sheath tumors. Neurosurg Focus 22: E12.

3. Stucky CC, Johnson KN, Gray RJ, Pockaj BA, Ocal IT, et al. (2012) Malignant peripheral nerve sheath tumors (MPNST): the Mayo Clinic experience. Ann Surg Oncol 19: 878-885.

4. Celli P, Cervoni L, Tarantino R, Fortuna A (1995) Primary spinal malignan schwannomas: clinical and prognostic remarks. Acta Neurochir (Wien) 135: 52-55.

5. Ducatman BS, Scheithauer BW, Piepgras DG, Reiman HM, Ilstrup DM (1986) Malignant peripheral nerve sheath tumors. A clinicopathologic study of 120 cases. Cancer 57: 2006-2021.
6. Amin A, Saifuddin A, Flanagan A, Patterson D, Lehovsky J (2004) Radiotherapyinduced malignant peripheral nerve sheath tumor of the cauda equina. Spine 29: E506-E509.

7. Adamson DC, Cummings TJ, Friedman AH (2004) Malignant peripheral nerve sheath tumor of the spine after radiation therapy for Hodgkin's lymphoma. Clin Neuropathol 23: 245-255.

8. Seppälä MT, Haltia MJ (1993) Spinal malignant nerve-sheath tumor or cellular schwannoma? A striking difference in prognosis. J Neurosurg 79: 528-532.

9. Carli M, Ferrari A, Mattke A, Zanetti I, Casanova M, et al. (2005) Pediatric malignant peripheral nerve sheath tumor: the Italian and German soft tissue sarcoma cooperative group. J Clin Oncol 23: 8422-8430.

10. Lang N, Liu XG, Yuan HS (2012) Malignant peripheral nerve sheath tumor in spine: imaging manifestations. Clin Imaging 36: 209-215.

11. Poyhonen M, Niemela S, Herva R (1997) Risk of malignancy and death in neurofibromatosis. Archives of pathology \& laboratory medicine 121: 139-143.

12. Evans DG, Birch JM, Ramsden RT, Sharif S, Baser ME (2006) Malignant transformation and new primary tumours after therapeutic radiation for benign disease: Substantial risks in certain tumour prone syndromes. J Med Genet 43: 289-294.

13. Evans DG, Huson SM, Birch JM (2012) Malignant peripheral nerve sheath tumours in inherited disease. Clin Sarcoma Res 2: 17.

14. Ziadi A, Saliba I (2010) Malignant peripheral nerve sheath tumor of intracranial nerve: a case series review. Auris Nasus Larynx 37: 539-545.

15. Xu Q, Xing B, Huang X, Wang R, Li Y, et al. (2012) Primary malignant peripheral nerve sheath tumor of the cauda equina with metastasis to the brain in a child: Case report and literature review. Spine J 12: e7-e13.

16. Cavanagh JB (1968) Effects of previous x-irradiation on the cellular response of nervous tissue to injury. Nature 219: 626-627.

17. Bergstrom $R$ (1962) Changes in peripheral nerve tissue after irradiation with high energy protons. Acta radiol 58: 301-312.

18. Sogg RL, Nikoskelainen E (1977) Parotid carcinoma and posterior fossa schwannoma following irradiation. Report of a patient treated in infancy for benign ear disease. JAMA 237: 2098-2100. 